\title{
Propriedades químicas do solo e desenvolvimento do coentro tratado com biofertilizante e cobertura de moringa
}

\begin{abstract}
O coentro destaca-se como cultura geradora de renda para agricultura familiar e orgânica. Através das técnicas de cobertura vegetal e aporte de nutrientes com biofertilizante é possível melhorar a fertilidade do solo, promover o bom desenvolvimento das plantas de coentro, e melhorar a renda dos agricultores. Desta forma, o objetivo foi avaliar as propriedades químicas do solo e o desenvolvimento do coentro sob aplicação de biofertilizante e cobertura de moringa. Foram estudadas 5 concentrações de biofertilizante associados a presença e ausência de cobertura vegetal de moringa em delineamento inteiramente casualizado. Foram mensuradas massa fresca e seca da parte aérea, altura, número de hastes e teor de clorofila das plantas de coentro e propriedades químicas para fins de fertilidade do solo ( $\mathrm{pH}, \mathrm{P}, \mathrm{K}, \mathrm{Na}, \mathrm{Ca}, \mathrm{Mg}, \mathrm{Al}, \mathrm{H}+\mathrm{Al}, \mathrm{CE}, \mathrm{MO})$. Realizou-se análise de variância e análise de regressão. A aplicação do biofertilizante e a presença de cobertura de moringa no solo influenciaram isoladamente todas as características agronômicas de desenvolvimento do coentro, mas não houve interação significativa entres e a presença de cobertura de moringa no solo influenciaram isoladamente todas as características agronômicas de desenvolvimento do coentro, mas não houve interação significativa entres os fatores de variação. Observa-se que a MFPA e a MSPA da cultura responderam linearmente às doses crescentes de biofertilizante, sendo $15 \%$ o tratamento com maior produção de massa lineares crescentes e o P, Al+3, H+Al e MO com tendências polinomiais decrescentes e não influenciaram as concentrações de $\mathrm{Ca}+2$ e $\mathrm{Mg}+2$. Na avaliação das plantas e das propriedades químicas do solo, os melhores resultados foram obtidos sob aplicação de $15 \%$ de biofertilizante e quando em solos cobertos por moringa.
\end{abstract}

Palavras-chave: Coriandrum sativum; Adubação orgânica; Conservação de solo.

\section{Chemical properties of the soil and development of the coriander treated with biofertilizer and moringa cover}

\begin{abstract}
Coriander stands out as an income-generating crop for family and organic farming. Through the techniques of vegetation cover and supply of nutrients with biofertilizer, it is possible to improve soil fertility, promote the good development of coriander plants, and improve farmers' income. Thus, the objective was to evaluate the chemical properties of the soil and the development of coriander under application of biofertilizer and moringa coverage. Five biofertilizer sacrifices associated with the presence and absence of moringa vegetation cover were studied in a completely randomized design. Fresh and dry shoot weight, height, number of pressures and chlorophyll content of coriander plants and chemical properties for soil fertility purposes were measured (hydrogen potential, phosphor, potassium, sodium, calcium, magnesium, aluminum, potential acidity, electric conductivity and soil matter organic). Analysis of variance and regression analysis were performed. The application of the biofertilizer and the presence of moringa cover in the soil lead all the agronomic characteristics of coriander development in isolation, but there was no interaction between the variation variations. It is observed that the fresh weight shoot and dry weight shoot of the crop responded linearly to the development in isolation, but there was no interaction between the variation variations. It is observed that the fresh weight shoot and dry weight shoot of the crop responded linearly to the gradual increase in biofertilizer influenced hydrogen potential, such as $\mathrm{K}+, \mathrm{Na}+$ and $\mathrm{EC}$ practices with increasing linear responses and $\mathrm{P}$, Al+3, potential acidity and SOM with decreasing polynomial tendencies and do not lead as calcium rules and magnesium. In the evaluation of plants and applied soil properties, the best results were chosen under the application of $15 \%$ biofertilizer and when in soils covered by moringa.
\end{abstract}

Keywords: Coriandrum sativum; Organic fertilization; Soil conservation.

Topic: Ciências do Solo

Reviewed anonymously in the process of blind peer.
Received: 02/01/2021

Approved: 25/01/2021
Brisa Ribeiro de Lima (iD

Instituto Federal Baiano, Brasil

http://lattes.cnpq.br/5875254881403004

http://orcid.org/0000-0001-5168-4797

brisalima2@hotmail.com

Enok Pereira Donato Júnior (ii

Instituto Federal Baiano, Brasil

http://lattes.cnpq.br/8549884751528347

http://orcid.org/0000-0003-1227-1417

enokcnn@hotmail.com

Felizarda Viana Bebé (id

Instituto Federal Baiano, Brasil

http://lattes.cnpq.br/9764329265812697

http://orcid.org/0000-0001-5459-6303

felizarda.bebe@ifbaiano.edu.br

\author{
Elcivan Pereira Oliveira \\ Instituto Federal Baiano, Brasil \\ http://lattes.cnpq.br/6174571140469591 \\ http://orcid.org/0000-0002-2454-9693 \\ elcivan_gbi@hotmail.com \\ Erinaldo Gomes Pereira (iv \\ Universidade Federal Rural do Rio de Janeiro, Brasil \\ http://lattes.cnpq.br/3637209801005675 \\ http://orcid.org/0000-0002-9052-091X \\ erinaldomn@yahoo.com.br \\ Erika da Costa Fernandes \\ Universidade Federal Rural do Rio de Janeiro, Brasil \\ http://lattes.cnpq.br/3351916397052664 \\ http://orcid.org/0000-0003-2960-1881 \\ erikac.fernands@gmail.com
}

Referencing this:

LIMA, B. R.; DONATO JÚNIOR, E. P.; BEBÉ, F. V.; OLIVEIRA, E. P.; PEREIRA, E. G.; FERNANDES, E. C.. Propriedades químicas do solo e desenvolvimento do coentro tratado com biofertilizante e cobertura de moringa. Revista Ibero Americana de Ciências Ambientais, v.12, n.1, p.1-10, 2021. DOI: http://doi.org/10.6008/CBPC21796858.2021.001.0001 


\section{INTRODUÇÃO}

O coentro (Coriandrum sativum L.) é originário do leste do Mediterrâneo e do Oriente Médio, pertencente à família Apiaceae (OLÍMPIO, 2017). Hortaliça tradicional da agricultura familiar, tem muitos produtores envolvidos com o seu cultivo durante todo o ano. Apresenta ciclo precoce e garante retorno rápido do capital investido, aumentando a renda das famílias envolvidas na exploração, tornando-se uma espécie de notável alcance social (FERREIRA, 2016; MOTA, 2013).

É uma olerícola largamente consumida no Brasil, principalmente na região Nordeste, assim como no território Sertão Produtivo da Bahia. Neste território $45,6 \%$ da população vive no campo e a agricultura familiar movimenta 90\% da economia (CODESP, 2016). No território a agricultura orgânica está em constante e exponencial expansão, diante da crescente demanda de alimentos saudáveis pelos consumidores locais.

Como resposta a essa demanda, a agricultura orgânica apresenta-se como uma oportunidade sustentável para a produção de hortaliças, com enfoque ecológico, rentável e socialmente justo (RESENDE et al., 2011). A autossustentação buscada na produção orgânica é a condição de perpetuamente colher biomassa de um sistema que não compromete sua capacidade de se renovar ou ser renovada (GLIESSMAN, 2001). E esta autossustentação pode ser alcançada por um conjunto de técnicas de manejo e dentre elas, destaca-se práticas conservacionistas de solo que incluem cobertura vegetal e aporte de nutrientes através de materiais orgânicos.

O biofertilizante líquido está entre as técnicas de fertilização alternativa que fornece nutrientes ao solo e promove o equilíbrio nutricional às plantas de maneira sustentável. É um bioinsumo natural obtido da fermentação de materiais orgânicos com água, contendo macro e micronutrientes para suprimento das plantas. Funciona como promotor de crescimento das plantas, atua na ciclagem de nutrientes e contribui para a melhoria das propriedades do solo (SILVA et al., 2011).

A cobertura vegetal é uma prática fundamental para a manutenção e aumento da fertilidade do solo. Dentre os vários materiais utilizados como cobertura vegetal, a parte aérea da Moringa oleífera é uma matéria-prima alternativa, que pode ser promissora por cobrir o solo e diante da alta concentração de nutrientes. Devido suas características de adaptação a climas tropicais, além de se adaptar a quase todo tipo de solo, conter na sua composição grande quantidade de nutrientes e possuir um bom poder de rebrota, a Moringa oleífera desponta como alternativa para as regiões semiáridas (OLIVEIRA JÚNIOR et al., 2009). Já é indicada como excelente forrageira para a pecuária e diante deste potencial de uso, propõe-se estudar a moringa como planta de cobertura de solo.

Estas técnicas permitem construir e/ou recuperar a fertilidade de solos, promover o bom desenvolvimento das plantas de coentro, e melhorar a renda dos agricultores, tornando-se uma ferramenta econômica e sustentável para adubação do solo, na agricultura familiar e orgânica. Diante disso, o objetivo do trabalho foi avaliar as propriedades químicas do solo e o desenvolvimento do coentro sob aplicação de biofertilizante e cobertura vegetal com Moringa oleífera. 


\section{MATERIAIS E MÉTODOS}

O experimento foi instalado no Setor de Agricultura do Instituto Federal de Educação Ciência e Tecnologia Baiano, Campus Guanambi, situado na zona rural do distrito de Ceraíma, situado nas coordenadas $14^{\circ} 13^{\prime} 30^{\prime \prime}$ S, 42 $46^{\prime} 53^{\prime \prime} \mathrm{O}$, à $525 \mathrm{~m}$ de altitude, clima semiárido (BSa) pela classificação de Köppen. 0 delineamento experimental foi inteiramente casualizado, em fatorial duplo $5 \times 2(0,2,5,10,15 \%$ de biofertilizante $x$ presença ou ausência de cobertura vegetal de moringa) em 3 repetições, totalizando 30 parcelas experimentais.

O solo utilizado foi classificado como Latossolo Vermelho-Amarelo distrófico, apresentando as seguintes propriedades químicas: $\mathrm{pH}: 6,43 ; \mathrm{P}: 3,9 \mathrm{mg} \mathrm{dm}^{-3} ; \mathrm{K}: 0,64 \mathrm{cmol}_{\mathrm{c}} \mathrm{dm}^{-3}$; $\mathrm{Na}: 0,04 \mathrm{cmol}_{\mathrm{c}} \mathrm{dm}^{-3}$; Ca: $2,2 \mathrm{cmol}_{\mathrm{c}} \mathrm{dm}^{-3} ; \mathrm{Mg}$ 0,9 $\mathrm{cmol}_{\mathrm{c}} \mathrm{dm}^{-3} ; \mathrm{Al}: 0,2 \mathrm{cmol}_{\mathrm{c}} \mathrm{dm}^{-3} ; \mathrm{H}+\mathrm{Al}: 4,12 \mathrm{cmol}_{\mathrm{c}} \mathrm{dm}^{-3} ; \mathrm{MO}: 0,24 \mathrm{dag} \mathrm{kg}^{-1} ; \mathrm{CE}: 0,91 \mathrm{dS}$ $\mathrm{m}^{-1}$. O solo foi peneirado em malha de $4 \mathrm{~mm}$ e adicionado aos vasos de $12 \mathrm{~L}$.

O biofertilizante foi confeccionado com $60 \mathrm{~kg}$ de esterco bovino, $5 \mathrm{~kg}$ folhas e galhos de mamoneira, $5 \mathrm{~kg}$ de pseudocaule de bananeira, $1 \mathrm{~kg}$ de rapadura, $0,5 \mathrm{~kg}$ de cinzas de madeira, $2 \mathrm{~L}$ de urina de vaca e $100 \mathrm{~L}$ de água, uma adaptação da metodologia descrita nas fichas agroecológicas do MAPA (MOREIRA et al., 2006). Os materiais foram depositados em tambor de $200 \mathrm{~L}$ e homogeneizados por 15 minutos, três vezes ao dia, durante 15 dias, com fermentação aeróbica. Após este período, o biofertilizante foi filtrado para a aplicação.

Para o preparo da cobertura vegetal fez-se a poda dos galhos mais tenros, folhas e flores de moringueira, o material foi triturado para reduzir o tamanho das partículas dispostas sobre o solo.

O experimento foi conduzido em casa de vegetação coberta. Foi realizada semeadura direta com sementes crioulas de coentro em covas de $1 \mathrm{~cm}$ de profundidade, espaçadas $5 \mathrm{~cm}$ entre plantas. Foram semeadas 6 sementes por cova, porém desbastadas para manter quatro plantas por cova, totalizando 32 plantas por vaso. Aos seis dias após o plantio ocorreu a germinação. Aos 10 dias após a semeadura fez-se o desbaste, adicionou-se a cobertura de moringa sobre a superfície do solo e realizou a aplicação de biofertilizante.

As plantas foram irrigadas com lâmina média de seis $\mathrm{mm}$ dia ${ }^{-1}$ com água de boa qualidade (condutividade elétrica: 0,04 dS m${ }^{-1}$ ) e foi aplicado biofertilizante em intervalos de 7 dias, nas concentrações de 2, 5, 10 e $15 \%$ de biofertilizante do volume de água aplicado. O biofertilizante concentrado apresentou condutividade elétrica de $10,3 \mathrm{dS} \mathrm{m}^{-1}$, devido a elevada quantidade de sais que o compunha. As diluições do biofertilizante na água utilizada para irrigação apresentaram $0,32 \mathrm{dS} \mathrm{m}^{-1} ; 0,68 \mathrm{dS} \mathrm{m}^{-1} ; 1,2 \mathrm{dS} \mathrm{m}^{-1}$ e 1,7 dS m $\mathrm{m}^{-1}$ respectivamente para as concentrações de 2, 5, 10 e $15 \%$.

Foi realizado o controle manual da vegetação espontânea, e não houve o controle de pragas e doenças pois não foram detectados danos ou sintomas visuais de ataque. Aos 37 dias após a semeadura, as plantas de coentro foram colhidas, com corte rente ao colo para avaliação. Foram escolhidas aleatoriamente oito plantas em cada parcela. As variáveis analisadas foram: produtividade $\left(\mathrm{kg} \mathrm{m}^{-2}\right)$, massa fresca da parte aérea - MFPA (g planta $\left.{ }^{-1}\right)$, massa seca da parte aérea - MSPA (g planta $\left.{ }^{-1}\right)$, altura da planta $(\mathrm{cm})$, número de haste, teor de clorofila. 
Foi contado o número de hastes das plantas, a altura foi determinada com auxílio de uma régua graduada. O teor de clorofila ou índice de clorofila Falker (ICF) foi determinado com o medidor eletrônico de clorofila ClorofiLOG modelo CFL 1030, aferida em 4 repetições. Para determinar a massa fresca da parte aérea, cortou-se a planta rente ao colo e pesou-se, em seguida este material foi encaminhado em sacos de papel para uma estufa de circulação de ar à $65^{\circ} \mathrm{C}$, até atingir massa constante para secagem e mensuração da massa seca da parte aérea. A produtividade foi calculada pela produção de massa fresca em razão da área cultivada $\left(\mathrm{kg} \mathrm{m}^{-2}\right)$.

Após a retirada das plantas dos vasos, foram coletadas amostras de solo com estrutura não preservada e junto com as amostras vegetais, foram encaminhadas para os laboratórios do IF Baiano, campus Guanambi.

As amostras de solo foram secas ao ar, destorroadas e peneiradas em malha de $2 \mathrm{~mm}$, para avaliação das seguintes propriedades: $\mathrm{pH}$ em água, solo: solução $(1: 2,5)$; fósforo disponível $(\mathrm{P})$, potássio $\left(\mathrm{K}^{+}\right)$e sódio

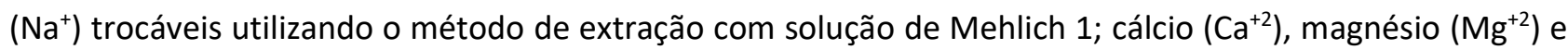
alumínio $\left(\mathrm{Al}^{+3}\right)$ utilizando o método da extração com solução de cloreto de potássio (KCl) a $1 \mathrm{~mol} \mathrm{~L}^{-1}$; acidez potencial $(\mathrm{H}+\mathrm{Al})$ extraída com solução de acetato de cálcio $\left(\mathrm{Ca}\left(\mathrm{C}_{2} \mathrm{H}_{3} \mathrm{O}_{2}\right)_{2}\right.$ a $0,5 \mathrm{~mol} \mathrm{~L}{ }^{-1}$ conforme Embrapa (2009).

$\mathrm{O}$ carbono orgânico total foi determinado com solução de dicromato de potássio $\left(\mathrm{K}_{2} \mathrm{Cr}_{2} \mathrm{O}_{7}\right)$ e a matéria orgânica (MO) calculada usando o fator de conversão de Van Bemmelen, segundo métodos adaptados de Yeomans et al. (1988, citado por MENDONÇA et al., 2005). A condutividade elétrica foi determinada pelo método de relação solo: solução (1:2) descrito por Souza et al. (2013).

Os resultados obtidos foram inicialmente submetidos testes de homogeneidade e normalidade, posteriormente à análise de variância para observar a interação dos fatores de variação, em seguida foi realizada análise de variância e médias comparadas pelo teste $\mathrm{F}$ a $5 \%$ de probabilidade para variáveis qualitativas e análise de regressão para variáveis quantitativas, ambos com auxílio do "software" SISVAR 5.6 (FERREIRA, 2019).

\section{RESULTADOS E DISCUSSÃO}

A aplicação do biofertlizante e a presença de cobertura de moringa no solo influenciaram separadamente todas as características agronômicas de desenvolvimento do coentro e algumas propriedades químicas do solo. Não houve interação significativa entres os fatores de variação em todas as variáveis avaliadas na planta e no solo. Este resultado corrobora com Gadelha et al. (2018) que avaliaram diferentes coberturas do solo e doses de biofertilizante aplicadas em alface e não mostraram a existência de interação significativa entre os dois fatores.

As repostas das plantas e do solo às diferentes concentrações de biofertilizante estão apresentadas por figuras, através de análise de regressão. Os resultados das plantas e do solo ao tratamento com e sem cobertura de moringa são explicados por tabelas, através de análise de variância e comparação de médias pelo teste $F(p<0,05)$. 
Observa-se que a MFPA e a MSPA da cultura responderam linearmente às doses crescentes de biofertilizante (Figura 1), sendo $15 \%$ o tratamento com maior produção de massa que alcançou valores

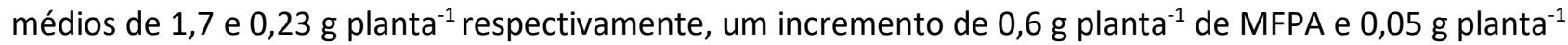
de MSPA quando comparadas as plantas controle (sem biofertilizante). Cardoso et al. (2017) observaram incremento de massa fresca em plantas de coentro quando aplicado biofertilizante líquido de esterco bovino à $10 \%$. Entretanto a aplicação de biofertilizante não acrescentou significativamente a produtividade, apresentando suave inclinação quadrática. Esta discrepância pode estar relacionada com a variação de massa dentro dos tratamentos.

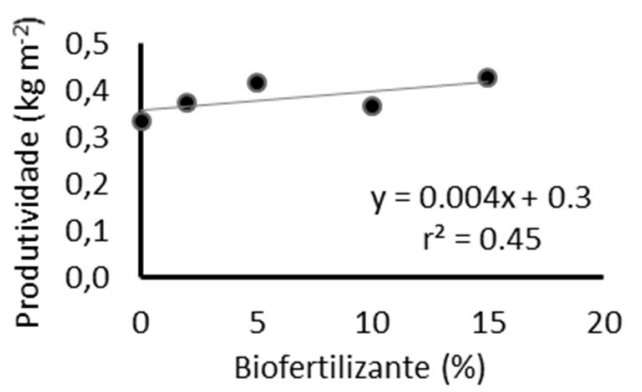

A

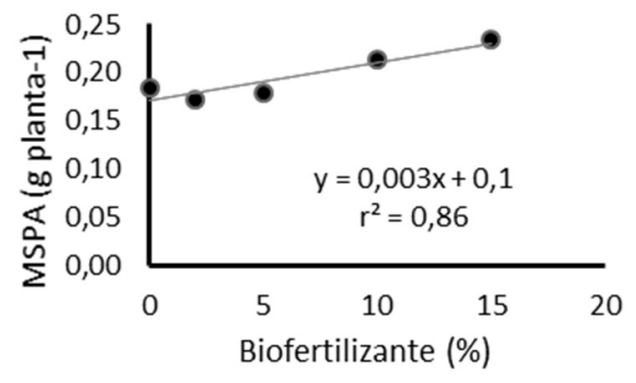

C

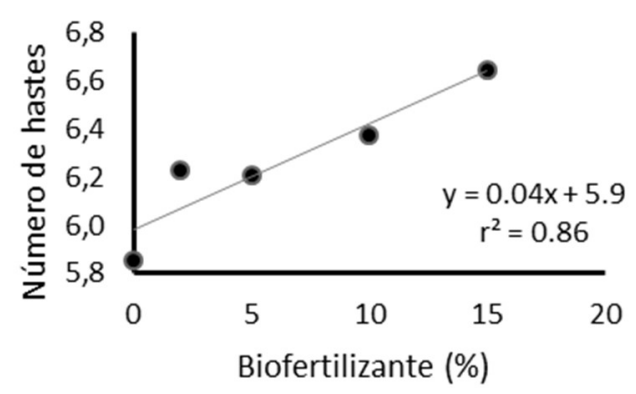

$E$

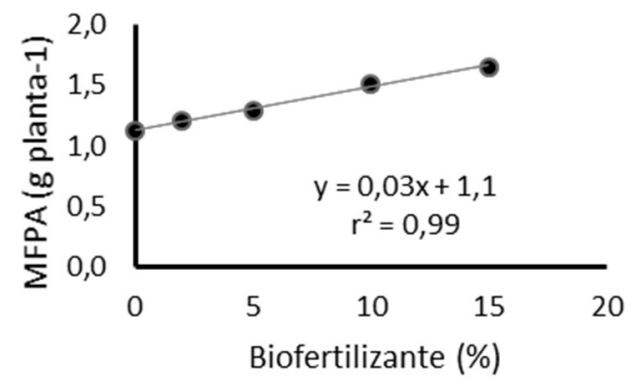

B

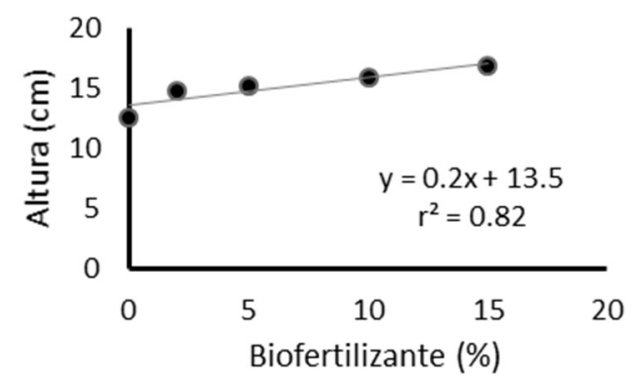

D

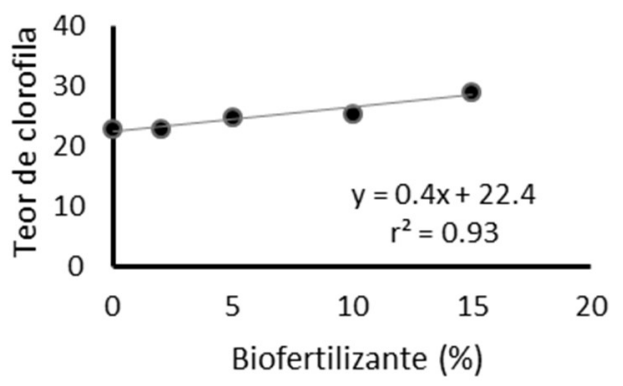

$\mathrm{F}$

Figura 1: Produtividade (A), Massa Fresca da Parte Aérea - MFPA (B), Massa Seca da Parte Aérea - MSPA

(C), Altura (D), Número de hastes (E) e Teor de clorofila (F) de plantas de coentro sob aplicação de biofertilizante.

A altura e o número de hastes das plantas de coentro foram influenciados positivamente pelas doses de biofertilizante, apresentando tendência linear e crescente à maior concentração estudada. Gaspar et al. (2019) testaram biofertilizante de manipueira em plantas de coentro e também observaram incremento na altura e o rápido crescimento inicial das plantas. $\mathrm{O}$ teor de clorofila das plantas apresentou resposta linear e crescente quando aplicadas doses de biofertilizante. 
A melhor reposta das variáveis agronômicas também pode estar relacionada com o aumento da área foliar (área fotossintética). A quantificação da clorofila é relevante no estudo de práticas culturais e de manejo visando aumentar o potencial fotossintético e rendimento das espécies. Uma planta com alta concentração de clorofila é capaz de atingir taxas fotossintéticas mais altas, produzir mais fotoassimilados e consequentemente são mais desenvolvidas e produtivas (MENEZES et al., 2017; TAIZ et al., 2017).

Quando se compara plantas com e sem cobertura (Tabela 1), a presença da cobertura incrementou 0,51 $\mathrm{kg} \mathrm{m}^{-2}$ na produtividade e 1,77 $\mathrm{g} \mathrm{planta}^{-1}$ na produção de MFPA. Para hortaliças folhosas como o coentro, a produção de massa fresca da parte aérea é muito importante, uma vez que suas folhas são o produto comercializado. Esta resposta pode estar relacionada com a eficiência de uso da água em solo protegido, uma vez que há menos perdas diretas de evaporação de água do solo e maior retenção de umidade no material vegetal de cobertura. Maggi et al. (2019) estudaram diferentes coberturas de solo no desenvolvimento de hortaliças, incluindo o coentro, e observaram um aumento de massa fresca e da altura de plantas cultivadas com cobertura de mandioca, aveia e mucuna.

Tabela 1: Valores médios das variáveis agronômicas do coentro cultivado com ou sem cobertura vegetal de moringa.

\begin{tabular}{lllllll}
\hline Tratamentos & $\begin{array}{l}\text { Produtividade } \\
\mathrm{kg} \mathrm{m}^{-2}\end{array}$ & $\begin{array}{l}\text { MFPA } \\
-- \text { g planta- }--\end{array}$ & $\begin{array}{l}\text { Altura } \\
\mathrm{cm}\end{array}$ & $\mathrm{N}^{\circ}$ de Hastes & Clorofila \\
\hline Com cobertura & 0,64 & 2,24 & 0,31 & 21,57 & 7,49 & 30,45 \\
Sem cobertura & 0,13 & 0,47 & 0,08 & 9,17 & 5,03 & 19,54 \\
\hline Valor F & $482^{*}$ & $217^{*}$ & $246^{*}$ & $221^{*}$ & $254^{*}$ & $40^{*}$ \\
\hline CV(\%) & 16,62 & 24,12 & 20,96 & 14,86 & 6,74 & 18,70 \\
\hline
\end{tabular}

MFPA: Massa Fresca da Parte Aérea; MSPA: Massa Seca da Parte Aérea. ns -não significativo; -significativo pelo teste $\mathrm{F}$ a $5 \%$ de probabilidade.

A presença da cobertura vegetal no solo retém a umidade, mitiga a evaporação e mantém a água disponível para a planta por mais tempo (MOTA et al., 2010; DALMAGO et al., 2009; STONE et al., 2006). A absorção dos nutrientes pela planta é resultado do fluxo de água no sistema solo-planta-atmosfera. O complexo sortivo de troca de íons solo-solução só ocorre na presença de água. Tendo em vista que no solo coberto há mais água disponível, acredita-se que consequentemente haverá maior disponibilidade de nutrientes na solução e possivelmente maior absorção dos íons pelas plantas.

Isto explicaria o aumento significativo das variáreis agronômicas das plantas de coentro cultivadas em solo coberto. A cobertura de Moringa permitiu um aumento de 390\% da produtividade, 370\% de MFPA, $280 \%$ de MSPA, $130 \%$ na altura, 49\% no número de hastes e $56 \%$ no teor de clorofila.

No solo, o aumento gradual das doses de biofertilizante influenciaram o pH, as concentrações de $\mathrm{K}^{+}$, $\mathrm{Na}^{+}$e $\mathrm{CE}$ com respostas lineares crescentes e o $\mathrm{P}, \mathrm{Al}^{+3}, \mathrm{H}+\mathrm{Al}$ e $\mathrm{MO}$ com tendências polinomiais decrescentes

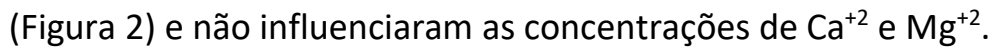

$\mathrm{O}$ pH do solo está intimamente ligado ao balanço dos íons diluídos na solução do solo. O biofertilizante promoveu o aporte de cátions $\left(\mathrm{K}^{+}, \mathrm{Ca}^{+2}, \mathrm{Mg}^{+2}\right)$ e ânions $\left(\mathrm{H}_{2} \mathrm{PO}_{4}^{-}\right)$oriundos das fontes orgânicas. O resultado deste complexo sortivo foi um $\mathrm{pH}$ com resposta linear às progressivas doses de biofertilizante. 


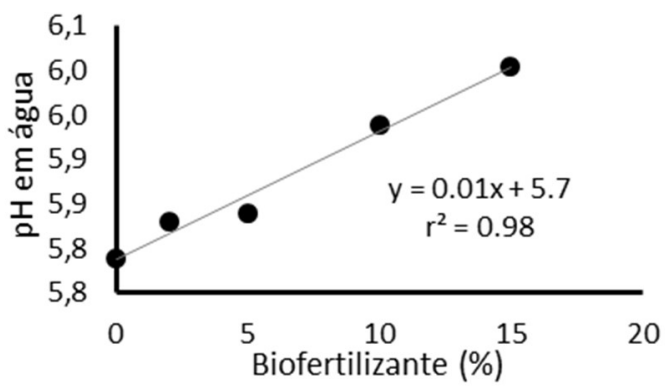

G

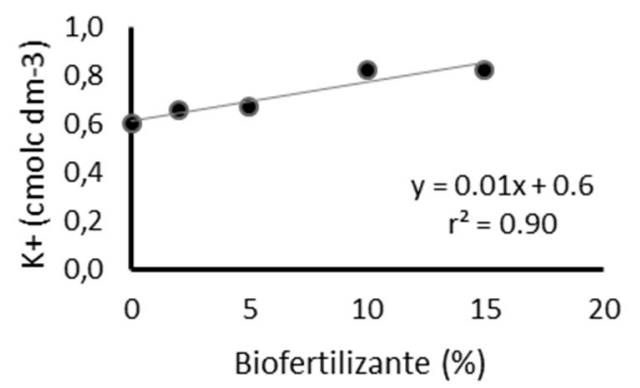

।

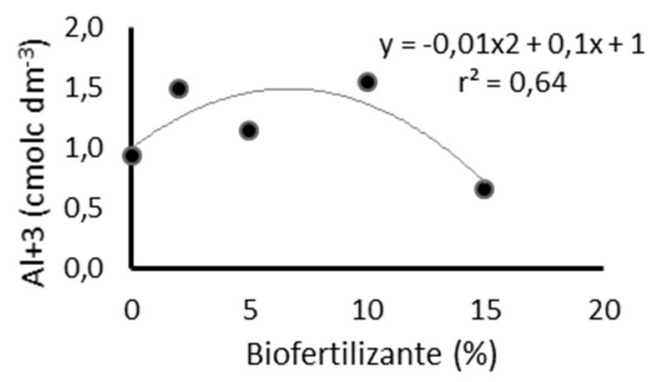

K

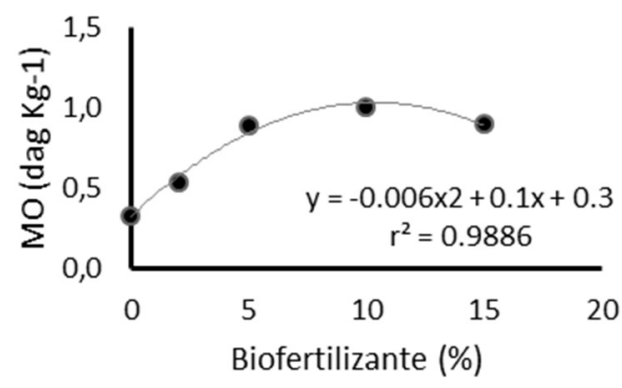

M

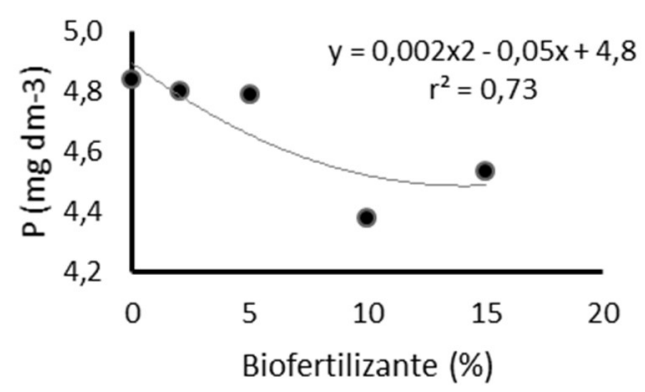

$\mathrm{H}$

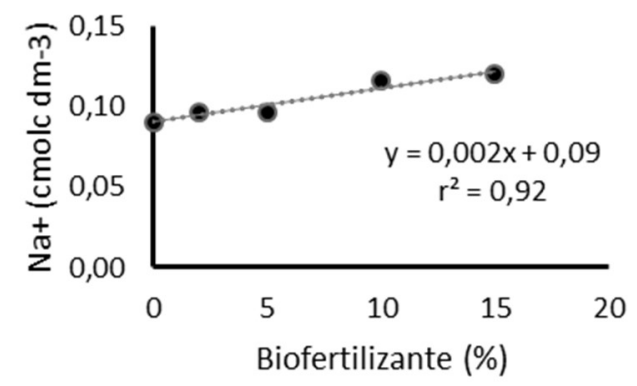

J

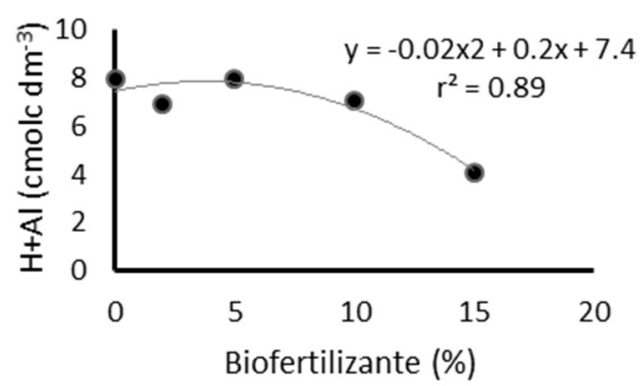

$\mathrm{L}$

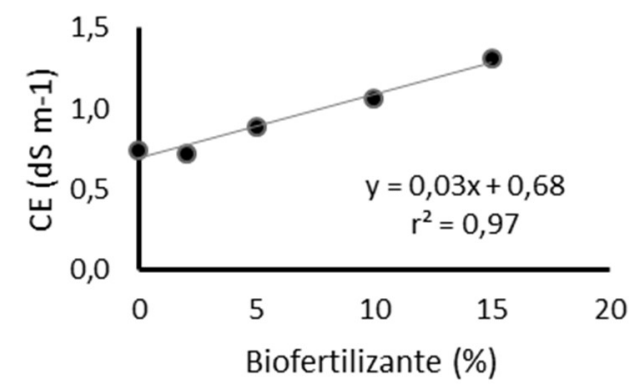

$\mathrm{N}$

Figura 2: $\mathrm{pH}$ em água (G), Fósforo disponível (H), Potássio trocável (I), Sódio trocável (J), Alumínio trocável (K), Acidez potencial (L), Matéria orgânica (M), Condutividade elétrica (N) de solos cultivados com plantas de coentro sob aplicação de biofertilizante. P: teor de P Mehlich-1; $\mathrm{K}^{+}$: potássio trocável; $\mathrm{Na}^{+}$: sódio trocável; $\mathrm{H}+\mathrm{Al}$ : acidez potencial; $\mathrm{Al}^{3+}$ : acidez trocável; $\mathrm{MO}$ : matéria orgânica; $\mathrm{CE}$ : condutividade elétrica.

Observa-se tendência decrescente do fósforo quando se aumenta as doses de biofertilizante. Este decréscimo pode estar associado à composição do biofertilizante. Alguns ingredientes como as cinzas possuem P na sua composição, porém em baixa concentração. Desta forma, é possível que as plantas ao se desenvolverem consumiram o fósforo existente, promovendo a queda das concentrações no solo. Outro destino para o fósforo neste solo pode ser a adsorção nos argilominerais, uma vez que se trata de um solo altamente intemperizado. Em contato com oxi-hidróxidos de Fe e Al, o P no solo pode desencadear adsorção ou complexos de superfície de esfera interna que fixa o $\mathrm{P}$ no solo e o torna não lábil. 
O aumento progressivo de doses de biofertilizante não alterou significativamente as concentrações de $\mathrm{Ca}^{+2}$ no solo (controle: $2,45 \mathrm{cmol}_{c} \mathrm{dm}^{-3} ; 2 \%: 2,68 \mathrm{cmol}_{c} \mathrm{dm}^{-3} ; 5 \%: 2,5 \mathrm{cmol}_{c} \mathrm{dm}^{-3} ; 10 \%: 2,47 \mathrm{cmol}_{c} \mathrm{dm}^{-3}$; 15\%: 2,58 $\left.\mathrm{cmol}_{\mathrm{c}} \mathrm{dm}^{-3}\right)$. $0 \mathrm{Mg}^{+2}$ também não apresentou variações significativas com o aporte de biofertilizante (controle: $2,21 \mathrm{cmol}_{c} \mathrm{dm}^{-3} ; 2 \%: 2,67 \mathrm{cmol}_{\mathrm{c}} \mathrm{dm}^{-3} ; 5 \%: 1,23 \mathrm{cmol}_{\mathrm{c}} \mathrm{dm}^{-3} ; 10 \%: 1,75 \mathrm{cmol}_{\mathrm{c}} \mathrm{dm}^{-3}$; 15\%: $1,8 \mathrm{cmol}_{\mathrm{c}} \mathrm{dm}^{-3}$ ). Este resultado pode estar associado a mobilidade destes elementos no solo e o uso destes nutrientes pelas plantas. O Mg é parte integrante da molécula de clorofila e observou-se anteriormente que os teores de clorofila nas plantas se mantiveram em tendência crescente. Logo, o aporte de Ca e Mg pelo biofertilizante foi suficiente para manter produtividade, mas não promoveu alterações no solo.

No biofertilizante o pseudocaule de bananeira e as cinzas de madeira são materiais fontes de K. Seus teores no solo apresentaram crescimento linear, mesmo o K sendo altamente móvel e facilmente lixiviado. As concentrações de sódio trocável responderam com pequeno aumento as crescentes doses de biofertilizante. Estes elementos, associados aos outros cátions ( $\mathrm{Ca}$ e $\mathrm{Mg}$ ) são responsáveis pelo aumento da CE. A condutividade elétrica do solo respondeu linearmente à medida que mais sais foram adicionados, com as maiores concentrações de biofertilizante na solução.

O alumínio e a acidez potencial $(\mathrm{H}+\mathrm{Al})$ dos solos apresentaram tendências quadráticas decrescentes, que indicam leve aumento das suas concentrações com a menor dose de biofertilizante e decréscimo a partir da concentração 5\%. Esta resposta está diretamente ligada ao aporte de cátions, que no complexo sortivo substituem os prótons $\left(\mathrm{H}^{+}\right)$na superfície do coloide, elevam o pH, e precipitam alumínio da espécie fitotóxica $\left(\mathrm{Al}^{+3}\right)$, reduzindo sua concentração com o aumento da concentração do biofertilizante. Além disso, o biofertilizante também promove aumento na atividade biológica do solo e esses organismos consomem parte do hidrogênio.

O teor de matéria orgânica do solo foi levemente alterado devido a composição do biofertilizante, feito com materiais ricos em carbono e nitrogênio de origem vegetal e animal. Destaca-se a cobertura vegetal de moringa que contribuiu para este incremento, não só pelo condicionamento da umidade, mas também pela decomposição gradual do material. Ressalta-se que o tempo de avaliação (37 dias) não é suficiente para completa decomposição do material, entretanto, os resultados já mostram um incremento positivo. Assis et al. (2016) avaliaram o efeito de biofertilizantes na produção da alface e observaram que o biofertilizante atuou como corretivo da acidez, proporcionou melhorias em propriedades químicas do solo e aumento significativo em todos os parâmetros fito-técnicos da alface analisados (número de folhas, área foliar, massa fresca da parte aérea e raiz, massa seca da parte aérea).

Na tabela 2 são apresentadas as propriedades químicas dos solos na presença e ausência de cobertura de moringa. O melhor desempenho das plantas no sistema de plantio com solo coberto é baseado em princípios ecológicos dentre eles o favorecimento na estocagem de carbono, a diminuição da infestação de plantas espontâneas, a diminuição da temperatura do solo, o aumento da biomassa microbiana e a maior economia de água (TAVELLA et al., 2010). 
Tabela 2: Propriedades químicas do solo cultivados com coentro com e sem a cobertura de moringa.

\begin{tabular}{lllllllllll} 
Tratamentos & $\mathrm{pH}$ & $\mathrm{P}$ & $\mathrm{K}$ & $\mathrm{Na}$ & $\mathrm{Ca}$ & $\mathrm{Mg}$ & $\mathrm{Al}$ & $\mathrm{H}+\mathrm{Al}$ & $\begin{array}{l}\mathrm{MO} \\
\mathrm{dag} \mathrm{kg}^{-1}\end{array}$ & $\begin{array}{l}\mathrm{CE} \\
\mathrm{dS} \mathrm{m}^{-1}\end{array}$ \\
\hline Com cobertura & 5,80 & 4,87 & 0,81 & 0,11 & 2,50 & 2,04 & 1,24 & 6,57 & 0,65 & 1,19 \\
Sem cobertura & 5,96 & 4,47 & 0,59 & 0,10 & 2,57 & 1,48 & 1,08 & 7,00 & 0,82 & 0,69 \\
\hline Valor F & $20,46^{*}$ & $6,67^{*}$ & $13,80^{*}$ & $5,36^{*}$ & $0,57^{\text {ns }}$ & $5,58^{*}$ & $0,13^{\text {ns }}$ & $0,27^{\text {ns }}$ & $0,91^{\text {ns }}$ & $27,05^{*}$ \\
\hline $\mathrm{CV}(\%)$ & 1,67 & 9,02 & 38,97 & 18,08 & 10,45 & 36,88 & 104,55 & 32,74 & 66,63 & 27,81 \\
\hline
\end{tabular}

Os componentes morfológicos da planta de coentro e as propriedades químicas do solo obtiveram resultados superiores quando submetidas à cobertura vegetal de moringa e adição de biofertilizante isoladamente. A complexa interação entre as propriedades do solo determina a sua fertilidade e influencia o desenvolvimento do coentro.

Solos sob aplicação de biofertilizante contém maior concentração de elementos essenciais e contribuem para o ótimo desenvolvimento da planta. Em solos cobertos, estes nutrientes são, juntamente com a água, melhor aproveitados pela planta, devido à maior eficiência de uso da água e elementos na solução do solo. Logo, melhores condições de fertilidade do solo, permitem que as plantas de coentro expressem seu potencial produtivo.

\section{CONCLUSÕES}

O desenvolvimento do coentro foi influenciado positivamente pelo biofertilizante. Os maiores valores de produtividade, MFPA, MSPA, altura, número de hastes e teor de clorofila foram obtidos na concentração $15 \%$, e quando cultivado em solo coberto por moringa o incremento foi ainda mais significativo.

A cobertura vegetal de moringa e a aplicação de biofertilizante à $15 \%$ influenciaram positivamente a dinâmica das propriedades químicas do solo, promovendo o incremento de nutrientes, com exceção do cálcio. Apesar de influenciarem isoladamente as plantas e o solo, a aplicação do biofertlizante e a cobertura de moringa não apresentaram interação significativa.

\section{REFERÊNCIAS}

ASSIS, B. P.; ASSIS, D. P.; GROSS, E.. Influência de biofertilizante na produção da alface e em propriedades químicas de um argissolo. Agrotrópica, v.28, n.1, p.47-54, 2016. DOI: http://doi.org/10.21757/01033816.2016v28n1p47-54

CARDOSO, M. O.; BERNI, R. F.; ANTÔNIO, I. C.; KANO, C.. Growth, production and nutrients in coriander cultivated with biofertilizer. Horticultura Brasileira, v.35, n.4, 2017. DOI: http://dx.doi.org/10.1590/S0102-053620170417

CODESP. Conselho de Desenvolvimento do Território Sertão Produtivo. Plano de desenvolvimento territorial rural sustentável e solidário do território sertão produtivo. Guanambi: CODESP, 2016.

DALMAGO, G. A.; BERGAMASCHI, H.; BERGONCI, J. I.; KRUGER, C. A. M. B.; COMIRAN, F.; HECKLER, B. M. M. Retenção e disponibilidade de água às plantas, em solo sob plantio direto e preparo convencional. Revista Brasileira de
Engenharia Agrícola e Ambiental, Campina Grande, v.13, p.855-864, 2009.

EMBRAPA. Empresa Brasileira de Pesquisa Agropecuária. Manual de análises químicas de solos, plantas e fertilizantes. Brasília: Embrapa Informação Tecnológica, 2009.

FERREIRA, D. F.. SISVAR: A computer analysis system to fixed effects split plot type designs. Revista Brasileira de Biometria, v.37, n.4, p.529-535, 2019. DOI: http://doi.org/10.28951/rbb.v37i4.450

FERREIRA, J. T. A.. Estudo econômico do cultivo consorciado de alface e coentro sob efeito de adubações organominerais. Monografia (Bacharelado em Agronomia) Universidade Federal de Campina Grande, Pombal, 2016.

GADELHA, P. H. M.; COSTA, F. C. L; SANTOS, F. S. S..

Cobertura morta do solo e doses de biofertilizante aplicadas em cobertura na produtividade da alface cv. elba. In: 
CONGRESSO NACIONAL DA DIVERSIDADE NO SEMIÁRIDO. Anais. Natal: UFRN, 2018.

GASPAR, G. V.; SILVEIRA NETO, J. W.. Avaliação do uso de manipueira como insumo para cultura de coentro-verdão (Coriandrum sativum). In: CONGRESSO LATINO-AMERICANO DE ENGENHARIA E SOCIEDADE, 1. Anais. São Paulo: USP, 2019.

GLIESSMAN, S. R.. Agroecologia: processos ecológicos em agricultura sustentável. 2 ed. Porto Alegre: UFRGS, 2001.

MAGGI, C.; MENDES, M.. Uso de Diferentes Coberturas de Solo em Sistema de Policultivo de Alface, Rabanete e Coentro. Cadernos de Agroecologia, v.14, n.1, 2019.

MENDONÇA, E. S.; MATOS, E. S.. Matéria orgânica do solo: Métodos de análises. Viçosa: UFV, 2005.

MENEZES, P. V.; COSTA, J. P. B. M.; MARQUES, I. C. S.; ALVES F. A. T.; OLIVEIRA, F. A.. Índice relativo de clorofila em pepineiro fertirrigado com soluções nutritivas salinas e enriquecidas com potássio. In: CONGRESSO INTERNACIONAL DAS CIÊNCIAS AGRÁRIAS, 2. Anais. Natal: Instituto Internacional Despertando Vocações, 2017.

MOREIRA, V. R. R.; CAPELESSO, E.. Orientações para uma Agricultura de Base Ecológica no Pampa Gaúcho. In: MAPA. Ministério de Agricultura, Pecuária e Abastecimento. Fichas Agroecológicas. Bagé: Instituto de Menores, 2006.

MOTA, J. C. A.; LIBARDI, P. L.; BRITO, A. S.; ASSIS JÚNIOR, R. N.; AMARO FILHO, J.. Armazenagem de água e produtividade de Meloeiro irrigado por gotejamento, com a superfície do solo coberta e desnuda. Revista Brasileira de Ciência do Solo, v.34, p.1721-1731, 2010.

MOTA, N. F.. Efeito do bokashi no crescimento da cebolinha, do coentro e em alguns atributos químicos e biológicos do solo. Dissertação (Mestrado em Agronomia) Universidade Federal do Ceará, Fortaleza, 2013.
OLÍMPIO, L. S.. Recipientes e densidades de cultivo na produção de coentro em ambiente protegido. Monografia (Bacharelado em Agronomia) - Universidade Federal do Ceará, Fortaleza, 2017.

OLIVEIRA JÚNIOR, S.; SOUTO, J. S.; SANTOS, R. V.; SOUTO, P. C.; MAIOR JÚNIOR, S. G. S.. Adubação com diferentes estercos no cultivo de moringa (Moringa oleífera LAM.). Revista Verde de Agroecologia e Desenvolvimento Sustentável, v.4, n.1, p.125-135, 2009. DOI: https://doi.org/10.18378/rvads.v4i1.159

RESENDE, A. L.; LIXA, A. T.; SANTOS, C. M. A.; SOUZA, S. A. S.; GUERRA, J. G. M.; AGUIAR-MENEZES, E. L.. Comunidade de Joaninhas em Consórcio de Couve com Coentro sob Manejo Orgânico. Revista Brasileira de Agroecologia, v.6, n.1, p.8189, 2011

SILVA, S. A.; CAVALCANTE, L. F.; SILVA, M. N. B.; BEZERRA, M. A. F.; NASCIMENTO, J. A. M.; SOUTO, A. G. L.. Biomassa seca de plantas de algodão colorido em solo com biofertilizante. Cadernos de Agroecologia, v.6, n.2, 2011.

SOUZA, E. R.; MELO, H. F.; ALMEIDA, B. G.; LEO, D. V. M.. Comparação de métodos de extração da solução do solo. Revista Brasileira de Engenharia Agrícola e Ambiental, v.17, n.5, p.510-517, 2013.

STONE, L. F.; SILVEIRA, P. M.; MOREIRA, J. A. A.; BRAZ, A. J. B. $P$.. Evapotranspiração do feijoeiro irrigado em plantio direto sobre diferentes palhadas de culturas de cobertura.

Pesquisa Agropecuária Brasileira, Brasília, v.41, n.4, p.577$582,2006$.

TAIZ, L.; ZEIGER, E.; MOLLER, I. M.; MURPHY, A.. Fisiologia e desenvolvimento vegetal. 6 ed. Porto Alegre: Artmed, 2017.

TAVELLA, L. B.; GALVÃO, R. O.; FERREIRA, R. L. F.; ARAÚJO NETO, S. E.; NEGREIROS, J. R. S.. Cultivo orgânico de coentro em plantio direto utilizando cobertura viva e morta adubada com composto. Revista Ciência Agronômica, Fortaleza, v.41, n.04, p.614-618, 2010.

A CBPC - Companhia Brasileira de Produção Científica (CNPJ: 11.221.422/0001-03) detém os direitos materiais desta publicação. Os direitos referem-se à publicação do trabalho em qualquer parte do mundo, incluindo os direitos às renovações, expansões e disseminações da contribuição, bem como outros direitos subsidiários. Todos os trabalhos publicados eletronicamente poderão posteriormente ser publicados em coletâneas impressas sob coordenação da Sustenere Publishing, da Companhia Brasileira de Produção Científica e seus parceiros autorizados. Os (as) autores (as) preservam os direitos autorais, mas não têm permissão para a publicação da contribuição em outro meio, impresso ou digital, em português ou em tradução. 